\title{
Evaluation of Medicines Forecasting and Quantification Practices in Various Public Sector Hospitals Using Indicator Based Assessment Tool
}

\author{
Mir Javid Iqbal ${ }^{1}$, Mohammad Ishaq Geer ${ }^{1 *}$, Parvez Ahamd Dar ${ }^{2}$ \\ ${ }^{1}$ Department of Pharmaceutical Sciences, University of Kashmir, Srinagar-190006, J\&K, India. \\ ${ }^{2}$ Department of Pediatrics, Govt. Medical College, Srinagar-190001, J\&K, India.
}

\section{ARTICLE INFO \\ Article history: \\ Received on: 11/08/2016 \\ Accepted on: 10/10/2017 \\ Available online: 30/12/2017}

\section{Key words:}

Evaluation, Forecasting, Quantification, Indicator, Assessment.

\begin{abstract}
An effective medicines quantification process seeks to ensure the availability of the right medicines in the right quantities, at reasonable prices, and at recognized standards of quality. This prospective study was carried out for a period of one year, from January 2013 to January 2014 to evaluate various medicines quantification practices prevalent at various public health facilities of District Srinagar, the summer capital of J\&K state. One super speciality children's tertiary care hospital, one Govt. Medical College Hospital, one District Hospital, one Sub District Hospital and one Primary Health Centre were selected for the study. A set of 27 qualitative and 05 quantitative indicators were developed, validated and used to study the availability of quantification data for forecasting needs, various quantification procedures/methods adopted and financial transactions involved in drug quantification practices. Indicator based assessment showed that, Average monthly consumption, distribution data, seasonal variations, stock in hand and purchase orders were used for assessment of quantification and forecasting of drug needs at study health facilities. Only Children's Hospital was found to have records for actual drug needs, however, current medicine usage records including daily patient visits and monthly work done reports were found to be available and accurate at every health facility surveyed. Average monthly consumption was used as a standard method for quantification in all facilities where as maximum and minimum stock levels were not defined including delayed payments resulting into frequent stock outs except at Children's Hospital. Quantitative assessment found the actual lead time of 30 days at Medical College Hospital followed by 25 days at District Hospital and 15 Days at Children's Hospital .
\end{abstract}

\section{INTRODUCTION}

Drug quantification is a process used to determine how much of a product is required for the purpose of procurement. But more specifically, quantification involves estimating not only the quantities needed of a specific item, but also the financial means required for purchasing the item. Accurate drug quantification requires various pieces of information, which include the Essential Medicines List (EML), average

\footnotetext{
* Corresponding Author

Dr. Mohammad Ishaq Geer, Dept. of Pharmaceutical Sciences, University of Kashmir,Srinagar-190006, J\&K, India.

Email: ishaqgeer @ gmail.com
}

consumption, epidemiological information, prescription patterns, minimum and maximum stock levels, frequency of stock-outs and length of the procurement cycle (MSH, 2009). The method for quantification should always be selected in light of the resources and information available. The morbidity method quantifies the theoretical quantity needed for the treatment of specific diseases (Osore, 1989; Allers, 2006. If no reliable information is available on past consumption or morbidity, medicine use can be extrapolated from the data of other facilities, regions, or countries (WHO, 1988). Quantification can be centralized, or decentralized to staff of peripheral warehouses and health facilities. The personnel and time requirements depend on the quality and accessibility of source data and on the type and scope of quantification (Hogerzeil, 1986). 
Logistic systems for public health facilities have been found inefficient and in many cases incapable of providing adequate supplies on a timely basis (Bates et al., 2000). It was found that out of the 100 percent budget allocated for medicines, 10 percent was lost through inadequate buying practices and 14 percent through quantification problems (Matse, 2005a).

Pharmaceutical supply systems in many developing countries including India have severe problems, including ineffective procedures in selection, poor quality control, and economically inefficient procurement (Holloway and Green, 2003). Literature review revealed that there is a paucity of published literature with respect to medicines management activities like drug selection, quantification, procurement, storage and distribution currently being followed in our public health facilities. Furthermore it was found that there are no performance measures/tools available by which our on-going medicines management activities at our public health facilities can be assessed and evaluated. Therefore this study was taken up to initiate a process of developing an indicator based assessment tool which can be used to carry out an in-depth assessment of the system and will help in providing information for targeted interventions in strengthening the system and current practices.

\section{OBJECTIVES}

$>$ To develop and validate an indicator based assessment tool using various national and international guidelines.

$>$ To carry out in-depth evaluation and assessment of current medicines quantification practices prevalent at study public health facilities.

\section{MATERIAL AND METHODS}

Qualitative cum semi-quantitative, descriptive, crosssectional approach was adopted for carrying out the study. This study design was followed to essentially ensure that the data acquired for the study could be evaluated, compared and measured so that qualitative cum quantitative postulations could be made.

The study was undertaken across the different levels of care including one super speciality Children's Hospital $(\mathrm{CH})$, one Govt. Medical College Hospital (MCH), one District Hospital (DH), one Sub District Hospital (SDH) and one Primary Health Centre (PHC). CH, MC, DH were the only healthcare facilities available in their respective categories in the selected district.

At the outset qualitative cum quantitative indicators were developed and validated for carrying out evaluation and assessment of quantification practices prevalent at study healthcare facilities. To understand, assess and evaluate medicines supply chain management in public health settings various methods and procedures as per national and international guidelines were identified during literature review (WHO1999; WHO 2006; Trap et al., 2010; Dargahi and Khosravi, 2010; Rutta et al., 2006). Relevance, significance, acceptability and applicability were used as preset criteria in selecting various tools/guidelines. Various elements and criteria for developing indicator based assessment tool were based on their Importance, measurability, reliability, and validity in the current settings.

Pretesting was done as per field pretesting method (Oksenberg et al., 1991) by carrying out a peer review at PHC and SDH as focus centers. Based on the pretesting outcome a set of 27 qualitative and 05 quantitative indicators in quantification were developed, validated and used to study the availability of quantification data for forecasting needs, various quantification procedures/methods adopted and financial transactions involved in quantification of drugs in public health facilities. The study was carried out in a stepwise and systematic manner as shown in Fig.1

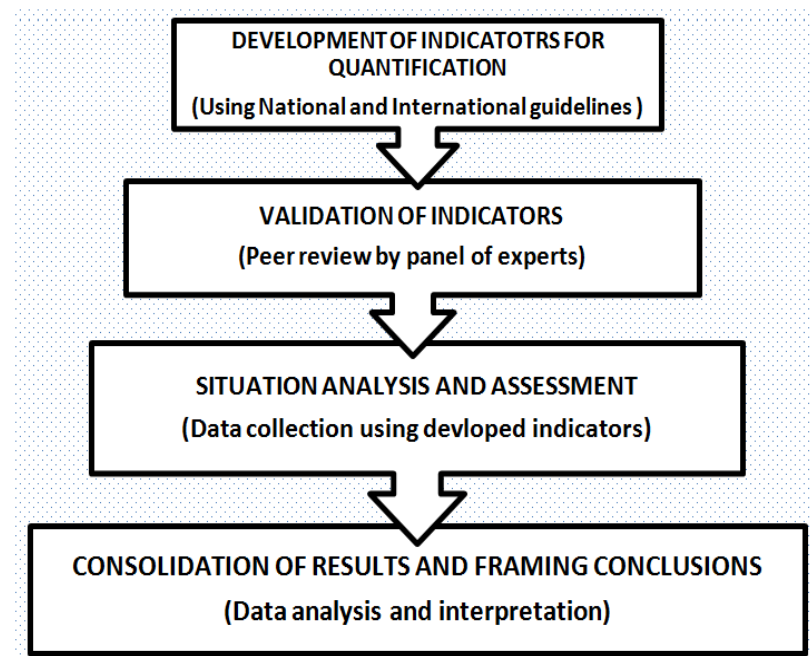

Fig. 1: Methodology adopted for indicator development and assessment.

\section{Statistical Analysis}

All data collected from qualitative and quantitative indicators during the study was captured in a Microsoft Excel and MS-Access spread sheets. Statistical analysis was of a descriptive nature with the responses to categorical variables summarized by frequency counts and percentages. All statistical procedures were performed on Statistical Analysis Software, Graphpad Instat 3.

\section{RESULTS}

Average Monthly Consumption (AMC), distribution data, seasonal variations stock in hand and purchase orders were used for quantification and forecasting of drug needs. Only $\mathrm{CH}$ had availability of proper records for actual drug needs however current medicine usage records including daily patient visits were found to be available and accurate at every health facility.

Table 2 of the present study gives an insight about the results obtained from various qualitative indicators used in the study. AMC data, distribution data, seasonal variations stock in hand and purchase orders were used for quantification and forecasting of drug needs. There was no formal committee or any standard process used for quantification and forecasting of drug needs at $\mathrm{CH}, \mathrm{MCH}$ and $\mathrm{DH}$. 
Table 1: Information used by public health facilities in the quantification and forecasting of drug needs.

\begin{tabular}{|c|c|c|c|c|c|c|}
\hline S. No. & Information Used & MCH & CH & DH & SDH & PHC \\
\hline 1. & Consolidating medicine requisitions & 2 & 2 & 2 & 2 & 2 \\
\hline 2. & Consolidating decentralized forecasts & NA & NA & NA & 1 & 1 \\
\hline 3. & Consolidating distribution data & 1 & 1 & 1 & 2 & 2 \\
\hline 4. & Average monthly consumption & 1 & 1 & 1 & 2 & 2 \\
\hline 5. & Donations provided by partners/donors & 1 & 1 & 1 & NA & NA \\
\hline 6. & Seasonal and regional variations & 1 & 1 & 1 & 2 & 2 \\
\hline 7. & Standard Treatment guidelines & 2 & 2 & 2 & 2 & 2 \\
\hline 8. & Quantities received & 2 & 2 & 1 & 2 & 2 \\
\hline 9. & Expired medicines & 2 & 2 & 1 & 2 & 2 \\
\hline 10. & Stock in hand & 1 & 1 & 1 & 1 & 1 \\
\hline 11. & Purchase orders & 1 & 1 & 2 & 2 & 2 \\
\hline 12. & Expiry dates & 1 & 1 & 1 & 2 & 2 \\
\hline
\end{tabular}

$1=$ Yes $\quad 2=$ No $\quad$ NA=Not Applicable.

Table 2: Qualitative indicator based assessment of various drug quantification practices at public health facilities.

\begin{tabular}{|c|c|c|c|c|c|c|c|}
\hline \multirow[t]{2}{*}{ S. No. } & \multirow[t]{2}{*}{ Qualitative Indicators } & \multicolumn{5}{|c|}{ Response } & \multirow{2}{*}{$\begin{array}{c}\text { Percent } \\
\text { Adherence }\end{array}$} \\
\hline & & MCH & CH & DH & SDH & PHC & \\
\hline \multicolumn{8}{|c|}{ AVAILABILITY OF DATA } \\
\hline & There is availability of current and accurate records of medicine needs. & 1 & 2 & 2 & 2 & 2 & 20 \\
\hline & There is availability of current and accurate records of drug consumption. & 1 & 1 & 1 & 1 & 1 & \\
\hline & Data and reports are maintainedregularly on outpatient attendances, inpatient bed-days. & 1 & 1 & 1 & 1 & 1 & 100 \\
\hline & Medicine demand estimation is done at the facility level. & 2 & 2 & 2 & 1 & 1 & 60 \\
\hline & $\begin{array}{l}\text { For many diseases reliable information exists on number of cases reported or treated } \\
\text { annually }\end{array}$ & 1 & 1 & 1 & 1 & 1 & 100 \\
\hline \multicolumn{2}{|r|}{$\begin{array}{l}\text { There is availability of Policies and Procedures Manual (SOPs) for quantification of } \\
\text { drugs. }\end{array}$} & 2 & 2 & 2 & 2 & 2 & $\mathbf{0}$ \\
\hline & Percentage adherence & 75 & $\mathbf{5 0}$ & 75 & 75 & 75 & 56 \\
\hline \multicolumn{8}{|c|}{ QUANTIFICATION MANAGEMENT } \\
\hline & A formal work plan and schedule for quantification exists. & 1 & 1 & 1 & 1 & 1 & 40 \\
\hline & $\begin{array}{l}\text { There is a quantification committee in place with all round involvement of all } \\
\text { stakeholders }\end{array}$ & 2 & 2 & 2 & 2 & 2 & $\mathbf{0}$ \\
\hline & If no then quantification is done by chief pharmacist & 1 & 2 & 2 & 2 & 2 & $\mathbf{0}$ \\
\hline & Warehouses and facilities have computerized quantification and inventory records & 2 & 2 & 2 & 2 & 2 & $\mathbf{0}$ \\
\hline & Pre-printed quantification data collection forms are used in the facilities. & 2 & 2 & 2 & 2 & 2 & 0 \\
\hline & All information on requisitions is complete, accurate, and written clearly & 2 & 2 & 2 & 2 & 2 & $\mathbf{0}$ \\
\hline & $\begin{array}{l}\text { Identified timelines in the supply chain that need to be taken into consideration in } \\
\text { product forecasting }\end{array}$ & 2 & 2 & 2 & 2 & 2 & 0 \\
\hline
\end{tabular}

\section{PROCEDURES/METHODS}

Percentage adherence 30

There is a method in place for quantification

Quantification is carried by AMC method

Stock out periods taken into consideration when calculating AMC

Order placed when stock balance is less than the minimum stock

Maximum stock calculated and fixed for each item

Actual procurement quantities \& costs are compared each year against initial quantification estimates.

Supply system does not face frequent or widespread pharmaceutical shortages.

Shortages do occur only in case of certain medicines

There is a hospital formulary that is used for quantification.

Adjustment in initial estimates is done to conform to budget realities.

Percentage adherence

$20 \quad 20 \quad 20 \quad 20$

\begin{tabular}{cccccc}
1 & 1 & 1 & 1 & 1 & $\mathbf{1 0 0}$ \\
1 & 1 & 1 & 1 & 1 & $\mathbf{1 0 0}$ \\
1 & 1 & 1 & 2 & 2 & $\mathbf{6 0}$ \\
1 & 2 & 2 & 2 & 2 & $\mathbf{6 0}$ \\
2 & 2 & 2 & 2 & 2 & $\mathbf{0}$ \\
1 & 1 & 2 & 2 & 2 & $\mathbf{4 0}$ \\
& & & & & \\
1 & 2 & 2 & 2 & 2 & $\mathbf{0}$ \\
1 & 1 & 1 & 1 & 1 & $\mathbf{1 0 0}$ \\
2 & 2 & 2 & 2 & 2 & $\mathbf{1 0 0}$ \\
1 & 1 & 1 & 1 & 1 & $\mathbf{1 0 0}$ \\
$\mathbf{7 0}$ & $\mathbf{7 0}$ & $\mathbf{5 0}$ & $\mathbf{3 0}$ & $\mathbf{3 0}$ & $\mathbf{6 0}$ \\
\hline
\end{tabular}

\section{ORDERING / FINANCIAL TRANSACTIONS TRACKING}

There is no discrepancy between actual and expected lead times.

There is no discrepancy between the value requisitioned and the value received.

Drugs and supplies needed are ordered in a timely manner

Drugs ordered are based on usage and expected needs of patients.

Percentage adherence

\begin{tabular}{cccccc}
2 & 2 & 2 & 2 & 2 & $\mathbf{0}$ \\
2 & 2 & 2 & 2 & 2 & $\mathbf{0}$ \\
1 & 2 & 2 & 2 & 2 & $\mathbf{2 0}$ \\
1 & 1 & 1 & 1 & 1 & $\mathbf{1 0 0}$ \\
$\mathbf{5 0}$ & $\mathbf{2 5}$ & $\mathbf{2 5}$ & $\mathbf{2 5}$ & $\mathbf{2 5}$ & $\mathbf{3 0}$ \\
\hline
\end{tabular}

1=Yes 2=No

Table 3: Quantitative indicator based assessment of various drug quantification practices at surveyed public health facilities.

\begin{tabular}{|c|c|c|c|c|c|c|}
\hline \multirow[t]{2}{*}{ S. No. } & \multirow[t]{2}{*}{ Quantitative indicators } & \multicolumn{5}{|c|}{ Response } \\
\hline & & MCH & CH & DH & SDH & PHC \\
\hline 1. & Frequency of carrying out $\mathrm{ABC} / \mathrm{VED}$ analysis. & $\mathrm{A}$ & $\mathrm{A}$ & $\mathrm{A}$ & - & - \\
\hline 2. & Frequency of carrying out medicine demand estimation & A & A & A & - & - \\
\hline 3. & Expected lead time in days & 10 & 10 & 10 & 5 & 5 \\
\hline 4. & Actual lead time in days & 20 & 30 & 25 & 1 & 1 \\
\hline 5. & Percentage of delayed hospital drug payments (one year) & 40 & 60 & 40 & NA & NA \\
\hline
\end{tabular}

$\mathrm{A}=$ Annually, NA=Not Applicable. 
Table 3 shows various quantitative indicators used in the study. These indicators showed that AMC method was used for quantification at $\mathrm{CH}, \mathrm{MCH}$ and $\mathrm{DH}$ whereas maximum and minimum stock levels were not defined anywhere.

Pharmacist's role was found to be subtle. Discrepancies were found in actual and expected lead times and also in values requisitioned and values received and there was no need-based ordering carried out except at $\mathrm{CH}$ hospital.

Financial constraints cause discrepancy in lead times and un-defined stock levels resulted in frequent stock-outs at these facilities.

Quantitative assessment revealed that maximum actual lead-time of 30 days was found at $\mathrm{MCH}$ followed by 25 days at $\mathrm{DH}, 15$ Days at $\mathrm{CH}$. However, a minimum of 2 days actual leadtime was found at SDH and PHC level. Delayed payments were found to be common and prevalent with highest number of 60 percent at $\mathrm{MCH}$ followed by 40 percent each at $\mathrm{CH}$ and $\mathrm{DH}$.

\section{DISCUSSION}

In many developing countries, logistic systems for public health facilities have been found inefficient and in many cases incapable of providing adequate supplies on a timely basis (Bates $\mathbf{J}$ et al., 2000). It was found that out of the 100 percent budget allocated for medicines, 10 percent was lost through inadequate buying practices, 14 percent through quantification problems (Matse, 2005). Table 1 of the present study shows thatAMC, distribution data, seasonal variations stock in hand and purchase orders were used for quantification and forecasting of drug needs. It would have been more appropriate to conduct regular drug utilization evaluation (DUE) studies on scientific lines to ascertain actual drug usage patterns and forecast needs.

Table 2 of the present study gives an insight about the results obtained from various qualitative indicators used in the study. AMC data, distribution data, seasonal variations stock in hand and purchase orders were used for quantification and forecasting of drug needs. There was no formal committee or any standard process used for quantification and forecasting of drug needs at $\mathrm{CH}, \mathrm{MCH}$ and $\mathrm{DH}$. Furthermore present study revealed that quantification and forecasting at these facilities was carried out locally by Medical Superintendents or Resident Medical Officers (RMO), however quantification and forecasting at PHC and SDH was done by collecting requisitions/indents annually. Present study suggests that the available methods need to be further assessed for their appropriateness and there should be a separate committee for quantification and forecasting drug needs. Furthermore there is a great need to emphasize on management information system because rational quantification and forecasting needs accurate records of previous drug consumption patterns, morbidity trends, identification of critical areas in the supply chain including calculation of lead times, re-order levels (RoL) and defined buffer stock levels.

Accurate quantification requires various pieces of information. These include the EML, average consumption, epidemiological (morbidity) information, prescription patterns, minimum and maximum stock levels, frequency of stock-outs and length of the procurement cycle (MSH, 2009). In a study carried out in Rwanda by Lijdsman et al., 2003, it was found that 95 percent of the facilities were using consumption data, while 14 percent used epidemiological data. Most facilities (95 percent) were using data on minimum and maximum stock levels in quantification. Moreover stock-out data was found to be used by only 41 percent of the health facilities in quantifying their health commodities. Furthermore eleven percent of facilities reported cross-checking quantification findings by using different quantification methods (Lijdsman et al., 2003).

Table 3 shows various quantitative indicators used in the study. These indicators showed that AMC method was used for quantification at $\mathrm{CH}, \mathrm{MCH}$ and $\mathrm{DH}$ whereas maximum and minimum stock levels were not defined anywhere. Pharmacist's role was found to be subtle. Discrepancies were found in actual and expected lead times and also in values requisitioned and values received and there was no need-based ordering carried out except at $\mathrm{CH}$ hospital. Financial constraints cause discrepancy in lead times and un-defined stock levels resulted in frequent stockouts at these facilities. This can be avoided locally by adhering to good quantification practices and defining stock levels with their respective lead times. At government level only qualified and trained human resource most importantly pharmacists should be recruited and there should be sufficient and regular disbursement of funds so that sufficient quantities of drugs are procured and made available to the patients.

Tayob, 2012 found that between 2009 and 2011, there was a 12 percent stock-out of the 45 ARVs on tendering that was measured in 9 provinces (405 items). There was also a 21 percent stock out of the $35 \mathrm{~TB}$ drugs on tendering in 9 provinces (315 items). Quite often poorly trained prescribers prescribe irrationally resulting in drug shortages. In Kenya, Matse determined that inadequately trained staff members are an important contributing factor to drug shortages as a result of their irrational prescribing (Matse, 2005b). A study conducted in the Mopani established that none of the workers understood the method they claimed to use to determine quantities to be ordered (Tayob, 2012). The stock outs and overstocking found in Mopani was attributed to the lack of knowledge with regard to quantification method (Matse, 2005b).

\section{CONCLUSION}

Indicator tool developed for carrying out evaluation and assessment of medicines quantification practices at various public sector hospitals was found to be valid, reliable, and measurable. The results of this study call for a change and improvement in the present drug management practices being followed in our public health care facilities. Appropriate measures need to be taken for proper quantification, distribution and safe use of medicines in accordance with well established guidelines and practices to make the supply chain more efficient and robust. There is a dire need to devise hospital specific medicine management policy framework 
which can guide hospitals in efficient management of medicine supplies. Allocation and disbursement of funds should also be sufficient and timely to cater to the needs of individual hospitals across all levels of care which would in turn help them to improve upon their medicines availability throughout the year without any stock outs.

\section{ACKNOWLEDGMENT}

We are thankful to the Medical Superintendents, doctors, pharmacists and other staff of health facilities surveyed for their support and cooperation. We are also thankful to all concerned officials of the Department of Health and Medical Education of $\mathrm{J} \& \mathrm{~K}$ state for giving statutory approvals for conducting this study.

Financial support and sponsorship: A note of thanks to the University Grants Commission, New Delhi for awarding Basic Scientific Research (BSR) Fellowship to the first author of this paper.

Conflict of Interests: There are no conflicts of interest.

\section{REFERENCES}

Allers C, Chandani Y. Guide for quantifying ARV drugs. Arlington, Va. Deliver for the U.S. Agency for International Development, 2006.Available at http://pdf.usaid.gov/pdf_docs/PNADG486.pdf (Accessed on November 20th 2016).

Bates J, Chandani Y, Crowley K, Durgavich J, Rao S. Implications of health sector reform for contraceptive logistics: a preliminary assessment for sub-Saharan Africa.2000. Available online at, http://www.popline.org/node/174270. (Accessed on $12^{\text {th }}$ November 2015).

Dargahi H., Khosravi SH. Hospitals pharmacy quality assurance system assessment in Tehran University of medical sciences, Iran. Iranian J Publ Health 2010; 39(4):102-13

Hogerzeil $\mathrm{H}$. Access to essential medicines as a human right. Essential Drug Monitor 2003; 33:25-26.

Holloway K, Green T. Drugs and Therapeutics Committees: A practical guide. World Health Organization department of essential drugs and medicines policy WHO/QSM; 2003.Available at http://apps.who.int/medicinedocs/documents/s17508en/s17508n.pdf(Acces sed on December 26th, 2015).

Lijdsman C, Onyango C, Gatera A, Saleeb S, Tarrafeta B, Gabra M. Assessment of the health commodity supply sector in Rwanda. USA. Arlington, Va.: Rational pharmaceutical management plus program, for USAID.2003. Available at http//.pdf.usaid.gov/pdf_docs/Pnadk130.pdf.(Accessed on December 10th, 2015).

Management Sciences for Health. International drug price indicator guide. Cambridge: Management Sciences for Health, 2012. Available

http://erc.msh.org/dmpguide/index.cfm?search_cat=yes\&display=yes\&mo dule $=$ dmp. . Accessed on January $\left.11^{\text {th }} 2016\right)$.

Matse PM. 2005b. Essential drugs at PHC, Book chapter 4.Available online

wiredspace.wits.ac.za/bitstream/handle/10539/1623/01Chapter4.pdf?(Acce ssed on September $30^{\text {th }}$ 2015).

Matse PM. Factors associated with drug shortages in PHC facilities in the Mopani district of the Limpopo Province 2005a (Doctoral dissertation, University of the Witwatersrand). Available at http://uir.unisa.ac.za/bitstream/handle/10500/13331/dissertation_zuma_sm .pdf? sequence $=1$ (Accessed on January $\left.11^{\text {th }} 2016\right)$.
MSH. Rational pharmaceutical management plus program (RPM Plus). A Guide for implementing the Monitoring-Training-Planning (MTP) Approach to build skills for pharmaceutical management. Arlington, Va.: Management Sciences for Health 2009. Available at http:// apps.who.int/medicinedocs/documents/s19629en/s19629en.pdf (Accessed on November $12^{\text {th }} 2015$ )

Oksenberg L, Cannell CF\& Kalton G. New strategies for pretesting survey questions. Journal of Official Statistics 1991; 7:349-65.

Osore, H. Estimating drug requirements using morbidity databased method: cumulative country experience. Trop Doc 1989;19: 90-94.

Rutta E, McCollum J, Mwakisu S. Rapid ART pharmaceutical management assessment in five mission hospitals in Tanzania. Management Sciences for Health; 2006. Available at http://projects.msh.org/projects/rpmplus/Documents/upload/Tanzania_Mis sion_Hospitals.pdf(Accessed on November $30^{\text {th }} 2016$ ).

Tayob S. Challenges in the management of drug supply in public health centres in the Sedibeng District, Gauteng Province 2012 (Doctoral dissertation, University of Limpopo (Medunsa Campus). Available http://ul.netd.ac.za/bitstream/handle/10386/683/SHAMIMA\%20TAYOB $\% 20$ FINAL\%20EXAM.pdf?sequence=1. (Accessed on November 14th, 2015).

Trap B, Hansen EH, Trap R, Kahsay A, Simoyi T, Oteba MO, Remedios V, Everard M. A new indicator based tool for Assessing and reporting on good pharmacy practice. Sout Med Rev 2010; 3(2):4-11.

WHO World Health Organization.International Pharmaceutical Federation.Developing pharmacy practice-A focus on patient care.2006. www.who.int/medicines/publications/WHO_PSM_PAR_2006.5.pdf.(Acce ssed on November 20th 2016).

WHO. The World Health Report. Shaping history. Annex Table 3: Burden of Disease in DALYs by cause, sex and mortality stratum in WHO regions, estimates for 2002. Geneva: World Health Organization, 2004; 126-31.Available at www.who.int/whr/2004/en/report04_en.pdf(Accessed on November 20th 2015).

WHO. World Health Organization. Procurement of vaccines for public-sector programmes: a reference manual. Geneva: WHO; 1999. $\mathrm{WHO/V} \& \mathrm{~B} / 99.12$. Available

pdf.usaid.gov/pdfdocs/Pnacn114.pdf(Accessed on December 10th, 2016).

WHO. World Health Organization. Estimating drug requirements: A practical manual. Geneva: WHO; 1988. WHO/DAP/88.2. Available apps.who.int/iris/bitstream/10665/62026/1/WHO_DAP_94.6.pdf.(Accesse d on December 10th, 2016).

\section{How to cite this article:}

Iqbal MJ, Geer MI, Dar PA. Evaluation of Medicines Forecasting and Quantification Practices in Various Public Sector Hospitals Using Indicator Based Assessment Tool. J App Pharm Sci, 2017; 7 (12): 072-076. 